\title{
Food subsidy or cash transfer: Impact of the food subsidy reform on Egyptian households ${ }^{1}$
}

\author{
Rana Hosni*, Racha Ramadan*
}

DOI: $10.30682 / \mathrm{nm} 1803 \mathrm{~b}$

JEL codes: C1, D12, Q18

\begin{abstract}
The Egyptian food subsidy system plays an important role in providing basic goods at low prices, to households, especially the poorest ones. However, the system has been through different reforms to decrease its cost and improve its targeting efficiency. This paper studies the impact of removing the rationed subsidized products and replacing it by cash transfers. Using the Egyptian Integrated Household Survey (HEICS - 2010/2011), a mixed demand model is used to estimate the own price, cross price and income elasticities. The estimated elasticities are used to compute the impact of the suggested reforms on households'welfare, measured by their food expenditures. The results show that the removal of subsidies will lead to an increase in the expenditures on free market goods for all income groups at both urban and rural areas, especially for the two lowest quintiles.
\end{abstract}

Keywords: Food Subsidies, Cash Transfer, Household's Consumption, Mixed Demand System, Egypt.

\section{Introduction}

Persistent poverty is one of the top economic challenges facing the Egyptian government with no general consensus about the best solution. According to the Household Expenditure, Income and Consumption Survey (HIECS) for 2014/2015; 27.8 percent of the population lived below the National Poverty Line (NPL) of 482 L.E./month per individual, compared to 25.2 percent in 2010/2011.

Subsidies are one of the most important tools of public policies to reduce poverty by providing basic goods to low-income individuals at prices lower than the market ones. Moreover, food subsidies have an important role in fighting malnutri- tion in Egypt; as it protects the poor from the impact of high food prices during turbulent periods. Subsidized food accounts for nearly fifth of poor households' food expenditures, hence its removal, without taking any other measures to mitigate any potential negative impacts, will jeopardize the households' welfare. In 2011, it was estimated that the removal of subsidies may lead to an increase in the national poverty estimates from 25.2 percent to about 34 percent (Al-Shawarby and El-Laithy, 2010; Breisinger et al., 2013).

However, the food subsidy system can be characterized by the existence of major fiscal and targeting obstacles. In FY 2014-2015, food subsidies represented $1.4 \%$ of GDP and $18.9 \%$ of total subsidies. Poverty data implies an in-

\footnotetext{
1 The authors acknowledge receiving data from the Central Agency for Public Mobilization and Statistics (CAPMAS) in Egypt. The authors are thankful to Professor Ahmed Kamaly for all his insightful comments.

* Faculty of Economics and Political Sciences, Cairo University, Giza, Egypt.

Corresponding author: racha.ramadan@feps.edu.eg.
} 
crease in the number of food-insecure Egyptians by more than 20 percent since 2009 and in poverty levels by more than 25 percent. Moreover, the Egyptian uprising in 2011 reflected the deterioration in both social and economic situation of Egyptian households. Inappropriate economic policies and weak management of public policies both have led to wide regional disparities and high variability of consumption patterns and poverty rates across different regions. For instance, equality levels varied according to the Gini coefficient from 0.35 in Cairo to 0.16 in Luxor (Oliver, 2015; Abid et al., 2016).

Hence, the increasing budget of the Egyptian subsidy system, along with the problems of targeting and leakage have led to several reforms of the Egyptian food subsidy system. In the actual system, food ration cards include more than 20 products such as sugar, oil, rice, chicken and many other products. While for the subsidized bread (baladi bread), the most important component of the food subsidies, it is not universally available anymore. Each household, who has ration cards, has access to 150 loaves of subsidized bread per month per person using smart card for bread (MSIT, 2014).

One of the suggested reforms is to replace the actual in-kind transfer program by cash transfers, especially after the success of the cash transfer system in reducing inequality and poverty in some of the Latin American countries (Fiszbein and Schady, 2009; Standing, 2012). Recently, Egyptian Ministry of Social Solidarity applied new cash transfer program called: "Takaful and Karama"2. However, the impacts of such program, on household income and food security levels, have not been studied yet. Applying cash transfer system will induce both negative and positive impacts on households' welfare. Cash transfers may decrease the leakage related to the actual system and provide households with an amount of money that may be spent on goods that are more necessary for them ${ }^{3}$. However, it may result in high inflation rate, in addition to targeting issues. More precisely; the important question to be asked is "who are the poor and how to reach them?».

Accordingly, studying the impacts of the removal of subsidies and the implementation of cash transfers, is needed to provide the policymaker with an insight on how the switch from an in-kind transfer subsidy system to a cash transfer system would affect the consumption behavior of households and hence, welfare and equity. Therefore, this paper is an attempt to study the impact of the removal of rationed products and its replacement by cash transfers on households' welfare measured by food expenditures. More precisely, the HEICS data for 2010/2011 is used to estimate a mixed demand model. Based on the estimated parameters, price and income elasticities of different rationed products and its free market counterparts are calculated taking into consideration the geographical locations and income groups of households. Such elasticities will be used to measure the impact of the subsidies reform on households' expenditures. The advantage of the mixed demand model is that it allows for the possibility of limited consumption levels for a subset of commodities, at a predetermined price (Gao et al., 1996; Matsuda, 2004) which corresponds to the case of the Egyptian subsidy system where some subsidized goods are available in rationed quantities (those included in the ration cards) and others are not limited in quantities and are available at free market price.

The closest study to our undertaking is Ramadan and Thomas (2011), who used individual-level consumption data from the 1997 Egyptian Integrated Household Survey (EIHS) to

\footnotetext{
2 Takaful is a conditional cash transfer program with attendance of $80 \%$ of school year for children aged 6-18, medical examinations for mothers and children under the age of six and attendance of nutrition classes. Karama is an unconditional transfer program to older persons and persons with disabilities. Under the umbrella of this program, poor families receive the equivalent of $\$ 43$ - \$83 a month, while some elderly and persons with disabilities receive $\$ 47$ per month. The program aims to cover 1.5 million households by the year 2017 (World Bank, 2015).

3 The Information and Decision Support Center of the Egyptian Cabinet (IDSC, 2012) reviews the subsidy system and presents the citizens' perception about the system. In February 2008, about $85 \%$ of citizens were unsatisfied with the system describing it as being insufficient in fulfilling their needs. In May 2011, about 19\% of those who acquire the ration cards faced usage problems. In addition, the report states that roughly $86 \%$ of citizens do not prefer the cash transfer system.
} 
estimate a mixed demand model. The estimated elasticities are used to compute the impact of modifying prices of subsidized wheat and bread on consumer's welfare. However, our study differs from Ramadan and Thomas (2011) analysis in several aspects. First, the paper uses a more recent dataset compared to the one used by Ramadan and Thomas (2011) which is HEICS (2010$2011)^{4}$. Second, the present research studies different food groups that do not include the subsidized bread studied by Ramadan and Thomas (2011). Finally, the welfare analysis differs between the two papers. Ramadan and Thomas (2011) studied the impact of the removal of bread and flour subsidies; given that these two subsidized products, mainly the bread, were the most important component of the system and they represented a critical challenge to the government's budget as Egypt imports more than 50\% of wheat consumption, in addition to the waste and leakage related to the bread supply chain. Moreover, Ramadan and Thomas (2011) takes into consideration the increase of the cereals prices given that their analysis was conducted just after the food crisis of 2008. The present study takes into consideration the new suggested reform of the food subsidy system by examining the impact of removal of subsidies of four rationed products (rice, sugar, oil and pasta) and replacing it by cash transfers on households' total expenditure. These welfare simulations are more relevant to the actual context of the Egyptian economy and the new suggested programs. Additionally, our analysis does not tackle the subsidized bread given the actual reform of the bread system, where subsidized bread is not universal anymore and it is available using only smart cards. Since the used data was conducted before this reform, we found that analyzing the bread as unrationed good is misleading and irrelevant.

The paper is organized as follows. Section two describes the Egyptian food subsidies by reviewing the history of its reform and then provides an overview of the literature on cash transfers. Section three describes the Mixed Demand Model.
Data and the estimation results are presented in section four. Finally, section five draws conclusions and provides recommendations.

\section{The Egyptian Food subsidies system}

The Egyptian subsidy system, covering mainly fuel and food products, is very costly. The subsidy bill reached nearly L.E. 234 billion in FY2014/2015, which represents 30 percent of total government expenditures, compared to L.E.150 billion in FY2011/2012, representing 32 percent of total government expenditures (MoF, 2013 and 2015). The Egyptian food subsidy system started after the Second World War. The system was divided into two sub programs; baladi bread program and ration card program. In 2013, baladi bread subsidies constituted 61 percent of food subsidies, while ration card-based commodities represented 39 percent (Breisinger et al., 2013).

The subsidized 82 percent flour and dark country-style bread, known as baladi bread, are the major commodities of the system given its importance in the Egyptian diet. The price of subsidized baladi bread is very low; typically less than 1 cent a loaf. It was a "universal" subsidy since bread was available to all consumers without restrictions (Ramadan and Thomas, 2011). Because most of the wheat used in the production of the subsidized bread is imported, this makes the bread subsidies budget vulnerable to the volatility of the international wheat price.

The second sub program of food subsidies is the ration card system. This system offers fixed monthly quota of some commodities per person for households holding the cards. These products are sold to the cardholders in specific outlets at a fixed price lower than the free market price. The commodities included in the card system vary over years yet sugar, oil, rice and tea are always available to households through the cards.

The system started during Nasser's regime with the aim of protecting all Egyptians (i.e. without targeting) from commodity shortages. This system had grown during Sadat's era then

\footnotetext{
${ }^{4}$ HEICS (2010-2011) is most the recent detailed dataset that the authors could have access to. There are other two more recent datasets (HEICS 2012/2013- HEICS 2014/2015), but the authors could not have access to their detailed versions for the conduct of the present empirical analysis.
} 
some reform measures were undertaken during Mubarak's era through; 1) reducing the number of commodities on the ration cards and, 2) the introduction of two tier ration card systems; fully subsidized (green card), and partially subsidized (red cards) (Ghoneim, 2012). In 2008, because of the food crisis, there has been a substantial increase in the number of ration cardholders. In 2009 , more than 80 percent of the population was included in the system (63 million ration cards holders) compared to 56 percent in 2004/2005 (40 million ration cards holders). The number of rations cardholders in 2014 increased to 66 million representing nearly 82 percent of the population. Moreover, the government replaced the ration card system with a smart card system. This new system has embedded chips that contain household's information and data on the household head's monthly quota of subsidized goods. Such reform enabled the government to track both the distribution and consumption of goods included in the system in an easy electronic method in order to reduce waste and leakage (World Bank, 2010; Ghoneim, 2012; MSIT, Monthly Bulletin, 2015).

The subsidy system has been characterized as inefficient because of excessive waste and an untargeted delivery system. Most of wealthy households hold the high subsidy green ${ }^{5}$ ration cards and not the low-subsidy red cards, and some of the poorest households hold red cards or no cards. Moreover, many of the poor households in Egypt cannot access ration cards; they face difficulties to obtain national ID numbers since they are illiterate (Ahmed and Bouis, 2002; FAO, 2009; Ramadan and Thomas, 2011 and Omar, 2012).

There is a significant literature studying the Egyptian food subsidy system and its reform. Kandil (2010) perceives the food subsidy system as inefficient since it leads to a huge waste of government resources without even targeting the right households, in addition to leakage and waste. She stressed on the need to restructure the system to provide the vulnerable segments with a choice between in-kind transfers or cash transfers. In addition, many other reforms have been suggested, such as the removal of subsidies on sugar and edible oil (Adams, 2000), mixing baladi flour wheat with maize flour at the milling phase to constrain leakage (Ahmed et al., 2001) and liberalizing the bread supply chain from the government intervention to reduce the leakage to the black market (Ramadan and Thomas, 2011). Al-Shawarby and El-Laithy (2010) estimated the cost of delivering $1 \mathrm{EGP}^{6}$ of food subsidies to consumers and calculated government savings to be up to 73 percent of the cost of food subsidies if system leakage is eliminated and coverage is narrowed.

Hence, the system has been through several reforms, to reduce its budget, waste, leakage, increase its efficiency and improve targeting. In 2014, the bread supply chain has been completely liberalized; the government intervenes only in the last stage of the bread supply chain to subsidize the consumers. Moreover, the bread is not universal anymore; a new system was implemented, which provides 150 loaves of subsidized bread per month per person per household using ration cards (MSIT, 2014). According to this new system, when individuals consume less than their quotas (5 loaves per day), they get points that can be exchanged with other subsidized products, in addition to their specific quotas of rationed products. While for the rationed products, the system aims to provide more balanced diets to the poor by extending the choice of commodities (FAO 2015; Ramadan, 2015).

Replacing in-kind transfer with cash transfers is largely seen as the best alternative for the actual system. The economic literature studying cash transfers and its advantages compared to in-kind transfers is extensive. Cunha (2010) used the Mexican government's Food Assistance Program (PAL) to try to compare both consumption and health outcomes under the two types of programs to differentiate between the costs and benefits of both the in-kind food and cash transfer programs. The paper provides no evidence that households resort to the consumption of

\footnotetext{
5 There are two types of ration cards; green and red. The green card has a high rate of subsidy for low-income households, while the red card has a low rate of subsidy intended for high-income households.

${ }^{6}$ The exchange rate in 2011: 1Euro $=8.4979$ (source: https://www.exchange-rates.org/Rate/EUR/EGP/9-1-2011).
} 
vices under cash transfers and that there is no difference in the total food consumption under the two programs. Nevertheless, data shows that households spend more on nutritious food such as; fruits and vegetables under the cash transfers scenario. In addition, the experiment proves that there could be sizable cost savings of replacing the PAL with a cash transfer program. Sivakul (2012) investigates the impact of in-kind compared to cash transfers on household consumption behavior in Bangladesh using a fixed effect instrumental variable model using data from three International Food Policy Research Institute (IFPRI) surveys conducted on the same cross section of households in years 2000, 2003, and late 2006-early 2007. Variables included in the estimation included; household size, household expenditure level, household daily calorie consumption, the proportion of stunted and underweight children aged 0 to 12 years old in a household, household beneficiary status (from either the in-kind or cash transfer programs), household eligibility status to each of the two programs. Results show that in-kind transfers lead to higher levels of wheat consumption than would be the case under an equal-valued cash transfers. Households who receive cash transfers without conditionality spend more on non-food items than those who are covered by in-kind transfers. The cash transfers are spent on items such as; children's education and clothes with no extra spending on negative items like smoking. The paper concluded that the paternalism concept might prove to have distortionary effects on household utility with no better effects on household long-term welfare levels.

Although the comparison between in-kind transfers and cash transfers has been extensively analyzed in the international literature, to our knowledge, there is an existing gap in the literature tackling the impact of cash transfers on Egyptian household's consumption and welfare. Cash transfers may be a good alternative to apply, especially for the poor ones. However, cash transfers system requires well-functioning markets and important amount of information to target the poor households. Moreover, it is important to analyze how the cash transfer amount will be spent within the household.
In the short run, cash transfer programs can be implemented gradually in addition to the inkind transfer system. In the longer term, such transfers could replace subsidies and be linked to price indexes to offset the effects of inflation (Breisinger et al., 2013). Cash transfers can be considered, in this case, as the minimum level of compensation to be given to the targeted households so that they are not worse off after the removal of subsidies. Compensation amounts would then vary according to the income category and perhaps geographic and other characteristics as well (Castel, 2012).

To achieve the desired goals of cash transfer programs, sufficient information about households, their consumption and their expenditures are required as well as clear communication mechanisms between the different members involved in these programs (Government Institutions and beneficiaries). Such amount of needed information and coordination efforts may increase the administrative budget of these programs. Additionally, there is a concern that cash transfers may be wasted by poor families through spending it on non-essential goods (Standing, 2012). Moreover, in case of high inflation and low market access, cash transfers may not have the expected positive results.

In light of the above literature, this paper is an attempt to study the impact of removing the food subsidies and imposing cash transfers on households' welfare in Egypt, measured by food expenditures. The paper follows Ramadan and Thomas (2011) by estimating a mixed demand model that takes into consideration the presence of products with specific quota at a lower price.

\section{The Mixed demand model}

Egyptian households have the choice to consume only the quota of the subsidized products or to complete such consumption by the free market counterparts of these products with the same quality or better quality. As the consumers have to choose, simultaneously, the consumption segment (below or above the quota) and the final consumption level, their consumption functions include non-linearity (Ramadan and Thomas, 
2011). Hence, the standard empirical demand analysis is not suitable to study such consumption behavior. Therefore, the present paper uses the mixed demand approach that provides more flexibility in the empirical analysis of the consumption behavior and takes into consideration the presence of goods with predetermined quotas (subsidized products in our case) and goods with unlimited quantities.

The mixed demand model allows for a range of possible specifications of the dependent and the independent variables between two polar cases: direct and inverse demand functions. The mixed demands are functions of prices and quantities. Such specification allows studying the impact of any change in the subsidy system (such as reducing quota, removing price subsidy, introducing cash transfers) on households' welfare (Ramadan and Thomas, 2011). It worth noting that mixed demands are different from the purely rationed ones; as in particular some markets do not clear in the case of purely rationed products. However, they share some similarities; compensated mixed demands are the same as compensated rationed ones (Chavas, 1984). The main difficulty with the mixed model arises from the requirement of having closed form expressions for the direct and indirect utility functions.

Following Moschini and Rizzi (2007) and Ramadan and Thomas (2011), consider $x=\left[x_{1} \ldots x_{n}\right]$, the vector of $n$ free market goods whose prices are determined on the market; $\mathrm{z}=\left[\mathrm{z}_{1} \ldots \mathrm{z}_{\mathrm{m}}\right]$ is the vector of $m$ rationed goods whose quantities are predetermined; $p$ and $q$ are the price vectors associated to $x$ and $z$, respectively. The mixed demand of a representative consumer is derived from the solution of the following maximization problem:

$$
\begin{aligned}
& m a_{x, q} \mathrm{x} u(x, y)-v(p, q, y) \\
& \text { s.t. } p^{\prime} x+q^{\prime} z=y
\end{aligned}
$$

where $u$ and $v$ are the direct and indirect utility functions respectively, and $y$ is the income or the total expenditures. Solving the first order conditions of the above maximization problem yields the vector of Marshallian mixed demands:

$$
\begin{aligned}
& x^{*}=x(p, z, y) \\
& q^{*}=q(p, z, y)
\end{aligned}
$$

At the optimum level, we get the following direct and indirect utility functions:

$$
u\left(x^{*}, z\right)=v\left(p, q^{*}, y\right) \equiv V^{M}(p, z, y)
$$

where $v^{\mathrm{M}}(\mathrm{p}, \mathrm{z}, \mathrm{y})$, is the mixed utility function, that can be derived from a cost function $\mathrm{C}(\mathrm{p}$, $\mathrm{z}, \mathrm{u}$ ) whose parametric specification satisfies the properties imposed by standard consumer theory. The total cost function to achieve a utility level $u$, given ( $\mathrm{p}, \mathrm{z})$, can be written as follows:

$$
C^{M}(p, z, u)=C(p, z, u)-\nabla_{z} C(p, z, u) \cdot z
$$

Using the mixed utility function, $\mathrm{V}^{\mathrm{M}}(\mathrm{p}, \mathrm{z}, \mathrm{y})$, the total cost function is called the mixed cost function and satisfies the following identity:

$$
C^{M}\left(p, z, V^{M}(p, z, y)\right) \equiv y
$$

As explained by Moschini and Rizzi (2006 and 2007), a flexible functional form of the cost function, such as the PIGLOG cost function used in the AIDS models, will not allow one to derive a closed form of the mixed utility function. Hence, they were able to overcome this drawback of the mixed demand system by choosing a cost function from the Gorman Polar form that is affine in $u$ (Moschini and Rizzi, 2007):

$$
C(p, z, u)=F(p, z)+G(p, z) u
$$

where $F$ and $G$ are Normalized Quadratic form continuous and differentiable in $p$ and $z$ :

$$
\begin{aligned}
& F(p, z)=\delta^{\prime} p+\left(a^{\prime} p\right)\left(\mu^{\prime} p\right) \\
& G(p, z)=\beta^{\prime} p+\left(a^{\prime} p\right)\left(\gamma^{\prime} z\right)+0.5\left(\frac{p^{\prime} \beta p}{a^{\prime} p}\right) \\
& +0.5\left(a^{\prime} p\right)\left(z^{\prime} \Gamma z\right)+p^{\prime} L z
\end{aligned}
$$

Using this specification, the mixed utility function can be derived from the mixed cost function in closed form as follows:

$$
\begin{aligned}
& V^{M}(p, z, y)=\frac{y-F(p, z)+\nabla_{z} F(p, z) z}{G(p, z)-\nabla_{z} G(p, z) z}= \\
& \frac{y-\delta p}{\beta^{\prime} p+0.5\left(\frac{p^{\prime} \beta p}{\left(a^{\prime} p\right)^{2}}\right)-0.5\left(a^{\prime} p\right)\left(z^{\prime} \Gamma z\right)}
\end{aligned}
$$


Finally, the structural equations of the budget shares of the unrationed goods $\left(W_{i}\right)$ and the rationed ones $\left(W_{k}\right)$ can be written as follows:

$$
\begin{aligned}
& W_{i}=\left[\delta_{i}+\left(\mu^{\prime} z\right) a_{i}+\left\{\beta_{i}+\sum_{j=1}^{n} \frac{\beta_{\mathrm{ij}} \mathbf{P}_{\mathrm{j}}}{\mathbf{a}^{\prime} \mathbf{p}}+\sum_{k=1}^{m} \lambda_{\mathrm{ik}} \mathbf{z}_{\mathrm{k}}+\mathbf{a}_{\mathrm{i}}\right.\right. \\
& \left.\left.\left[\gamma^{\prime} z-0.5\left(\frac{\mathbf{p}^{\prime} \mathrm{Bp}}{\left(\mathrm{a}^{\prime} \mathbf{p}\right)^{2}}\right)+0.5\left(\mathrm{z}^{\prime} \Gamma \mathrm{z}\right)\right]\right\} v^{m}\right] * \frac{p_{i}}{y}+\varepsilon_{i}(9) \mathrm{i}=1, \ldots . \mathrm{N} \\
& -W_{k}=\left[\left(a^{\prime} p\right) \mu_{k}+\left[\left(a^{\prime} p\right) \gamma_{k}+\left(a^{\prime} p\right) \sum_{s=1}^{m} \gamma_{k s} z_{s}+\sum_{j=1}^{n} \lambda_{j k} p_{j}\right] v^{m}\right] \\
& * \frac{z_{k}}{y}+\zeta_{i} \\
& \text { (10) } \mathrm{k}=1, \ldots \mathrm{M}
\end{aligned}
$$

where, $a=\left(a_{1}, \ldots a_{N}\right)^{\prime}$ is a vector of arbitrarily chosen coefficients in order to impose the homogeneity condition. The error terms, $\varepsilon_{i}$ and $\zeta_{i}$, are assumed to be identically and independently distributed. Parameters to be estimated are the $\mathrm{N}$-vectors $\delta$ and $\beta$, the M vectors $\mu$ and $\gamma$. There is as well the $\mathrm{NxN}$ matrix $\mathrm{B}=\left[\beta_{\mathrm{ij}}\right]$, the $\mathrm{MxM}$ matrix $\Gamma=\left[\gamma_{\mathrm{ks}}\right]$ and the NxM matrix $L=\left[\lambda_{i j}\right]$. Homogeneity and symmetry conditions imply the following parametric restrictions:

$$
\begin{aligned}
& \sum_{i=1}^{N} a_{i}=1 ; \beta_{i j}=\beta_{j i} ; \gamma_{k s}=\gamma_{s k} ; \sum_{i=1}^{N} \delta_{i}=1 \\
& \sum_{i=1}^{N} \beta_{i}=1 ; \sum_{i=1}^{N} \beta_{i j}=0 ; \sum_{j=1}^{N} \lambda_{j k}=0 \\
& i, j=1, \ldots . N \quad \text { and } \mathrm{k}, \mathrm{s}=1, \ldots \mathrm{M}
\end{aligned}
$$

\section{Data and Estimation Results}

The system of share equations (9) and (10) is estimated using the Egyptian Integrated Households Survey (HEICS-2010/2011) conducted by Central Agency Public Mobilization and Statistics (CAPMAS). HEICS is representative of the Egyptian population in the five regions of the country (Metropolitan, Lower Urban, Lower Rural, Upper Urban, and Upper Rural). The survey contains household- (and individual-) level variables on housing characteristics, food expenditures (subsidized and not subsidized), non-food expenditures, education, health status, wage employment, credit and savings, farming, livestock ownership, and non-farm enterprises. For the present paper, we use $50 \%$ of the HEICS (2010/2011) sample ${ }^{7}$, mainly the section on household's consumption and expenditures for subsidized and non-subsidized products. It is worth noting that this is not the most recent available household survey. However, this is the most detailed data set the authors can have access to.

The present analysis will focus on eight products; four rationed goods (rice, sugar, oil and pasta) and its free market counterparts. It is worth noting that the present analysis does not include bread consumption. This can be explained by the fact that the bread was subsidized but not rationed till March 2014, which in our case should be treated as a good with predetermined price but unlimited quantity. However, with the new reform of the system, the bread became available using specific cards and there is a quota of consumption per household. Accordingly, we found that analyzing the subsidized bread as an "unrationed good" can be misleading and irrelevant after the recent reform of the system.

The four rationed products, rice, sugar, oil and pasta, are the most important ones in the card system. They have been always present in the system. On average, the subsidized oil represents $19 \%$ of the household's total subsidies expenditure. While sugar and rice represent $14 \%$ and $10 \%$, respectively. Finally, the subsidized pasta represents the lowest share of subsidies expenditure with less than $0.50 \%{ }^{8}$. The total expenditures spent on these four products and their free counterparts will be used as a proxy for the total income. The average total expenditures on these 8 products is EGP 51 with an average share of $40 \%$ for the subsidized rationed products compared with an average of $60 \%$ for the free market products (Table 1).

For the rationed products; subsidized oil represents the highest share with an average of $16 \%$ of total expenditures on these eight products, followed by subsidized sugar with an average of $13 \%$. For the free market products, the rice came at first level with an average share of $20 \%$

\footnotetext{
7 The authors acknowledge receiving the data ( $50 \%$ of the sample) from the CAPMAS.
}

${ }^{8}$ Shares computed from the HEICS sample used in the mixed model. 
Table 1 - Descriptive Statistics of the shares of the rationed and non-rationed products.

\begin{tabular}{|l|c|c|c|c|}
\hline \multicolumn{1}{|c|}{ Item } & Mean & Std. Dev. & Min & Max \\
\hline Subsidized Rice & 10,61 & 13,31 & 0,00 & 75,50 \\
Subsidized Oil & 16,13 & 14,95 & 0,00 & 82,64 \\
Subsidized Sugar & 12,75 & 12,93 & 0,00 & 100,00 \\
Subsidized Pasta & 0,19 & 1,56 & 0,00 & 24,74 \\
\hline Share of subsidized products & 39,68 & 34,79 & 0,00 & 100,00 \\
\hline Free Market Rice & 19,89 & 21,84 & 0,00 & 89,24 \\
Free Market Oil & 10,98 & 15,55 & 0,00 & 81,82 \\
Free Market Sugar & 14,06 & 19,01 & 0,00 & 100,00 \\
Free Market Pasta & 15,36 & 11,79 & 0,00 & 78,26 \\
\hline Share of Free Market products & 60,30 & 34,79 & 0,00 & 100,00 \\
\hline
\end{tabular}

Source: Computed by the authors using HEICS 2010/2011.

followed by the pasta with an average share of $15 \%$. The subsidized pasta is the lowest consumed among the rationed products; this may be explained by its low quality compared to the free market pasta (Table 1).

Ration consumption differs according to the different quintiles. Table 2 shows that $93 \%$ of the lowest quintile consumes rationed goods. Although this share decreases at the highest quintile, there is $38 \%$ of the households of high-income group that consumes rationed products. This shows that the ration system is suffering from leakage to the high-income group.

Using HEICS data, the system of share equations (9) and (10) is estimated with all explanatory variables normalized by their sample mean. To avoid the use of more sophisticated methods to deal with the issue of frequent zero expenditures for some food items, the system of equations is estimated using average shares at the governorate level for the different quintiles in urban and rural areas, instead of the household level, using Seemingly Unrelated Regression (SUR) criterion, and imposing cross-equation restrictions such as symmetry, adding up and homogeneity constraints. As the share equations sum up to one, one of the equations was dropped to avoid singularity of the residual covariance matrix. Parameters of dropped equations are recovered using the
Table 2 - Distribution of Households according to Ration Products Consumption (\%).

\begin{tabular}{|l|c|c|}
\hline Quintile & $\begin{array}{c}\text { Not Consuming } \\
\text { Ration products }\end{array}$ & $\begin{array}{c}\text { Consuming } \\
\text { Ration products }\end{array}$ \\
\hline 1 & 6,77 & 93,23 \\
\hline 2 & 15,33 & 84,67 \\
\hline 3 & 29,48 & 70,52 \\
\hline 4 & 46,39 & 53,61 \\
\hline 5 & 62,06 & 37,94 \\
\hline Total & 31,92 & 68,08 \\
\hline
\end{tabular}

Source: Computed by the authors using HEICS 2010/ 2011.

homogeneity and symmetry constraints (Ramadan and Thomas, 2011; Krishnan et al., 2017). Following Moschini and Rizzi (2007), we set the coefficients of vector (a) equal to the mean share of the different unrationed products.

Using the estimated parameters from the mixed demand model $^{9}$, price and income elasticities are computed at the mean of the prices, the quantities and the total expenditure of different quintile levels in urban and rural areas. Table 3 shows that free market rice, free market sugar and free market pasta are necessity goods for all the quintiles in both urban and rural areas with income elasticities varying from 0.11 for the pasta in the

\footnotetext{
9 The estimated parameters are not presented in the paper for ease of presentation but they are available upon request.
} 
third quintile in rural areas to 0.94 for sugar in the lowest quintiles in rural areas. Oil is highly elastic for the two lowest quintiles in both urban and rural areas. For the rationed goods, we found that all income groups consider rice as an inferior good. This may be expected given the low quality of the rationed products, compared to the free market one. And the oil is considered as an inferior good as well for the two lowest quintiles in both urban and rural areas. Surprisingly, subsidized sugar and pasta are necessity goods with positive income elasticity; however, their income elasticities are lower than their free market counterparts (Table A1 in the Appendix).

According to the own price elasticities of free market goods; pasta and oil are highly elastic goods. The oil elasticity differs from the estimated one in Ramadan and Thomas (2011). They found that oil reacts weakly to its price. This shows the change in the consumption pattern of oil by Egyptian households. Our results show as well, that the increase in sugar price is not expected to decrease its consumption. This is close to what was found by Ramadan and Thomas (2011); as they found that sugar acts weakly to its price. We found similar results for rice, at all income levels. The inelasticity of both sugar and rice can be explained by the importance of both rice and sugar in the Egyptian dietary system. Moreover, according to the cross price elasticities, sugar is considered as a complement to rice and oil at all income levels (Table A2 in the Appendix).

Rationed goods are highly inelastic for all income levels (Table A3 in the Appendix). The estimated elasticities are zero for some goods such as the own price elasticity for pasta and cross price elasticities for rice and sugar with respect to pasta's price. These weak elasticities show that the consumption of these rationed goods are not driven by its price.

For the relation between the free market products and its rationed counterparts, we can define complementary or substitution relations based on price elasticities, as follows. If $x_{n}$ is an unconstrained good with unit price $\mathrm{p}_{n}, \mathrm{z}_{\mathrm{k}}$ and $\mathrm{x}_{\mathrm{n}}$ are substitutes (respectively complements) if $\left(\frac{\delta_{\mathrm{q}_{\mathrm{k}}}}{\delta_{\mathrm{p}_{\mathrm{n}}}}\right)\left(\frac{\mathrm{p}_{\mathrm{n}}}{\mathrm{q}_{\mathrm{k}}}\right)>0($ respectively $<0)$ and
$\left(\frac{\delta_{\mathrm{x}_{\mathrm{n}}}}{\delta_{\mathrm{z}_{\mathrm{k}}}}\right)\left(\frac{\mathrm{z}_{\mathrm{k}}}{\mathrm{x}_{\mathrm{n}}}\right)<0($ respectively $>0)$ (Madden, 1991; Ramadan and Thomas, 2011). Therefore, our results show that free market rice and subsidized rice are substitutes. We also found that the free market rice and the subsidized oil are complements. Moreover, subsidized pasta is a substitute to both free market pasta and free market rice. While for sugar and oil, the cross elasticities are almost zero between the free market product and its rationed counterpart. This can be explained by the difference in quality between the two types (Table A4 and A5 in the Appendix).

Finally, the estimated elasticities are used to compute the change in the household's consumption behavior resulted from the removal of subsidies. In other words, we compute the change in the expenditure share of each product resulted from the removal of subsidies, assuming that the income level of the households and the price level of the free market goods did not change ${ }^{10}$. Our results show that the removal of subsidies will yield an increase in the expenditures of free market goods for all income groups in both urban and rural areas. The lowest and second quintiles will be the most affected by such removal. In urban areas, total expenditure will increase by $36 \%$ and $24 \%$ for the first and second income quintile, respectively. While in rural areas, total expenditure for the first and second income quintiles will increase by $33 \%$ and $37 \%$ respectively. This shows that the actual system is playing an important role in supporting food expenditures of poor households. However, the increase in the expenditures of the fifth quintile, especially in rural areas, prove that some households of the highest quintiles are getting benefit of such system and that there is a clear leakage in the system (Figure 1).

The removal of food subsidies is expected to increase the expenditures devoted to free market goods, in order to compensate the decrease in the consumption of the rationed goods. Hence, this may be considered as a deterioration of the

\footnotetext{
${ }_{10}$ This assumption is a strong one given that such increase in the demand for free market goods to compensate the removal of the subsidies may lead to an increase in their prices.
} 
Figure 1 - Change in Total Expenditure resulted from Subsidies Removal (\%).

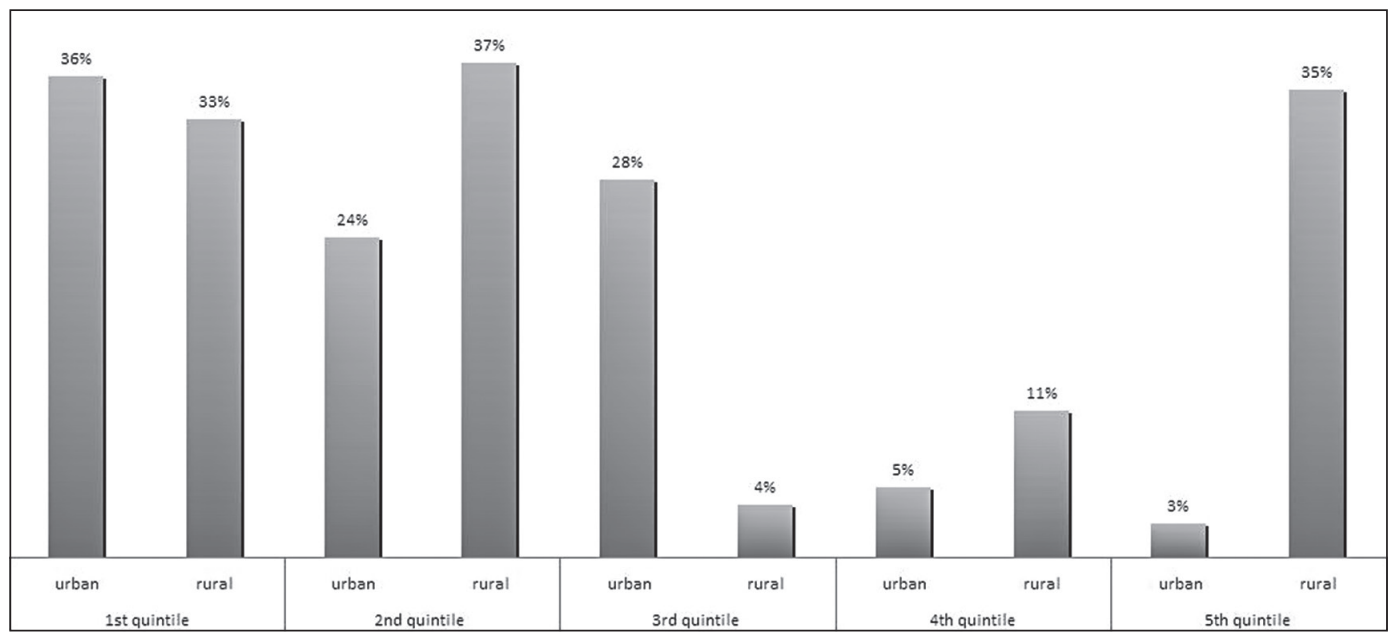

Source: Computed by the authors using HEICS 2010/2011.

household's welfare since the household will be obliged to spend more on these food products in order to maintain the same level of consumption. Moreover, such increase in food expenditures may negatively affect the households' expenditures on other services, such as education and health.

As explained above, in order to mitigate the negative impact of removing subsidies on households' consumption behavior, cash transfers may be a good alternative to apply, especially for the poor ones. Accordingly, we attempted to measure the impact of the introduction of cash transfers equivalent to the amount of the rationed product expenditures, on households' consumption behavior. In other words, we measured the change in the consumption of the different free market goods resulted from the cash transfer. We assumed that cash transfers would be delivered only to the two lowest quintiles in both urban and rural ones. It is found that the increase in income will be spent, mainly, on rice and oil. The increase in consumption for both, first and second quintile in rural areas, is higher than the increase for urban areas. For instance, rice consumption will increase in rural areas by $49 \%$ and $37 \%$ for the first and second quintiles, respectively, compared to $15 \%$ and $17 \%$ for the first two quintiles in urban areas. This shows the importance of the role played by the social pro- tection programs, food subsidies or cash transfer, in the rural areas.

\section{Concluding remarks and discussion}

The food subsidy system has been playing an important role in reducing poverty and food insecurity in Egypt. However, the system is not well-targeted to poor households and represents a real burden on the government budget. Hence, the system had been through different reforms in order to improve its efficiency and reduce its budget. Given the success of the cash transfer programs in Latin American countries, such programs have been seen as the best alternative for the actual system in Egypt. This paper is an attempt to study the impact of the removal of food subsidies, mainly rationed goods, on Egyptian households' consumption patterns.

Using the HEICS data (2010/2011), a mixed demand model was used to estimate income and price elasticities. Then, the estimated elasticities were used to compute the change in household's expenditures in case of subsidies removal and applying cash transfers. The choice of the mixed demand approach was driven by the specificity of the Egyptian food subsidy system; as the mixed demand model is flexible in defining consumer's demand as a function in both prices and quantities. 


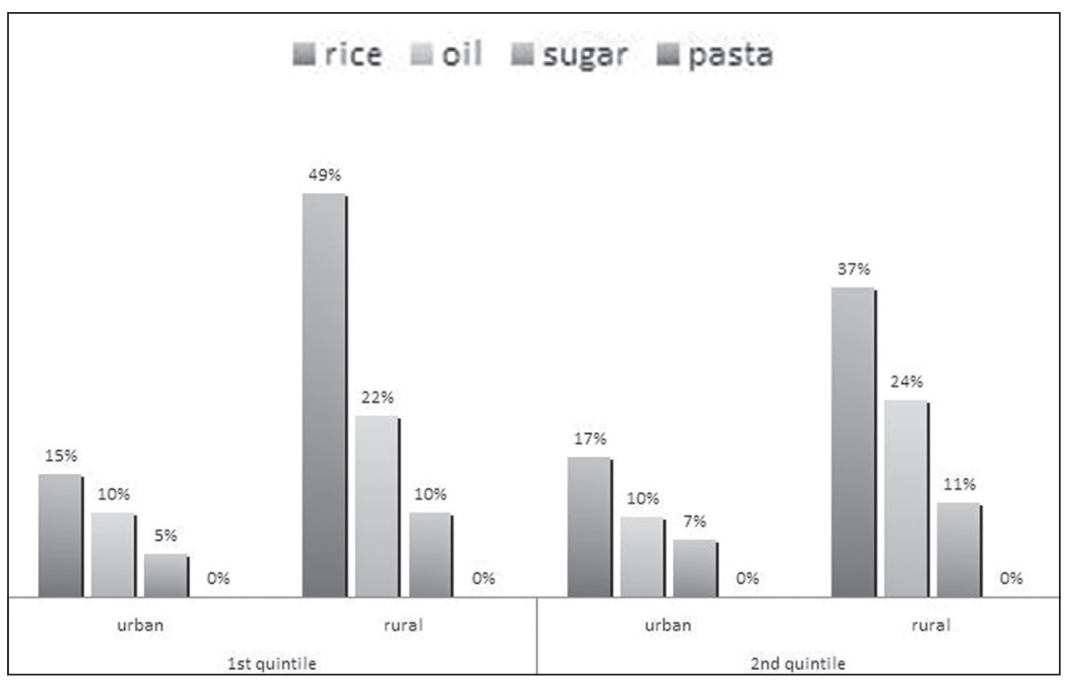

Figure 2 - Change in Free Market Goods Consumption due to Cash Transfer.

Source: Computed by the authors using HEICS 2010/2011.

Our results found that subsidized oil and rice are inferior goods. And the consumption of the rationed products reacted weakly to their prices. Given the difference in quality; the cross price elasticities for sugar and oil are almost zero between the free market ones and its rationed counterparts. Moreover, and as found in the literature, the removal of food subsidies without any protective measures for the poor, will yield to an increase in the households' total expenditure, at all income levels in urban and rural areas, to keep the same level of their consumption. This means a decrease in their welfare. However, the poor households will be the most affected in both urban and rural areas. Providing cash transfers to the most affected households in the two lowest quintiles in urban and rural areas, will lead to an increase of the consumption of mainly rice and oil, especially for the rural areas.

Therefore, food subsidies are playing significant role in providing poor households the basic goods, especially in rural areas, instead of all its problems related to its increasing budget, waste and leakage. Accordingly, any change in the system has to be made gradually to offset any negative effects that may result. This matches the recent conducted reforms to the system in Egypt that the government implements to decrease the system's budget and increase its efficiency. In fact, the actual food subsidy system can be considered to be a "semi-cash" system as the govern- ment provides households with a given monthly amount through the smart rationed card that the beneficiary households can use to purchase several rationed goods. Moreover, the government of Egypt implements new cash transfer programs such as "Takaful" and "Karama".

However, it is worth noting that more research is needed to study the impact of such reforms and new programs on the households' welfare. The cash transfers system requires well-functioning markets and important amount of information in order to target the poor households. Furthermore, cash transfers may result in an increase in the prices levels causing inflation rate to rise. And the transferred amount can be spent on other goods than food items, which may affect negatively the food security of households, especially that of children. It cannot thereby be concluded that the cash transfer system is the best alternative of the actual system in Egypt without research-based evidence about the impact of the system on food consumption, in addition to consumption of other goods and services.

Finally, the authors are aware of the different caveats related to such analysis. First, the used data in the analysis were surveyed before the new reform of the subsidized bread. Hence, new analysis should be conducted using new survey after the implementation of the reform to study its impact on households' welfare and the resulted change in consumers' consumption behavior. 
Second, the estimation of the model at the governorate/quintile levels prevents the inclusion of socio-economic characteristics of the households. Such characteristics would be important to be integrated in order to improve the targeting of the system. Finally, the inclusion of nonfood expenditures, such as education and health, would be relevant to study how the removal of the subsidies and the application of cash transfers would affect the expenditures of other goods and services. These caveats might be considered as future research questions that require more updated data and further investigation.

\section{References}

Abid Y., O'Donoghue C. and Sologon D., 2016. Exploring the Determinants of Welfare Distribution in Tunisia and Egypt Using a Welfare Generation Model, Working Paper No. 1009, Economic Research Forum.

Adams R., 2000. Self-Targeted Subsidies: The Distributional Impact of the Egyptian Food Subsidy System, The World Bank.

Ahmed A.U., Bouis H.E., Gutner T. and Lofgren H., 2001. The Egyptian Food Subsidy System Structure, Performance, and Options for Reform, Research Report 119, International Food Policy Research Institute Washington, D.C.

Ahmed A.U. and Bouis H.E., 2002. Weighing What's Practical: Proxy Means Testing for Targeting Food Subsidies in Egypt, Food Consumption and Nutrition Division of the International Food Policy Research Institute, Discussion Paper BRIEFS, Discussion Paper 132.

Al-Shawarby S. and El-Laithy H., 2010. Egypt's Food Subsidies: Benefit Incidence and Leakages, Social and Economic Development Group, Middle East and North Africa Region, The World Bank. Available at: http://dar.aucegypt.edu/handle/10526/3211.

Breisinger C., Al-Riffai P., Ecker O., Abuismail R., Waite J., Abdelwahab N., Zohery A., El-Laithy H., and Armanious D., 2013. Tackling Egypt's Rising Food Insecurity in a Time of Transition. Joint IFPRI-WFP Country Policy note.

Castel V., 2012. Reforming Energy subsidies in Egypt, African Development Bank.

Chavas J.-P., 1984. The Theory of Mixed Demand Functions, European Economic Review, 24, (3): 321-344.

Cunha J.M., 2010. Testing Paternalism: Cash vs. Inkind Transfers in Rural Mexico", Working paper, Stanford University.
Food and Agriculture Organization, 2009. Mission Findings and Recommendations Inter-Agency Assessment Mission - November-December 2008, Initiative on Soaring Food Prices.

Food and Agriculture Organization, 2015. FAO GIEWS Country Brief on Egypt, http://www.fao. org $/$ giews $/$ countrybrief/country.jsp? code $=$ EGY.

Fiszbein A. and Schady N., 2009. Conditional Cash Transfers: Reducing Present and Future Poverty, Washington DC: The World Bank.

Gao X.M., Wailes E.J., Cramer G.L., 1996. Partial Rationing and Chinese Urban Household Food Demand Analysis, Journal of Comparative Economics, 22(1): 42-62.

Ghoneim A.F., 2012. The Political Economy of Food Price Policy in Egypt, UNU-WIDER, Working Paper No. 2012/96.

Kandil M., 2010. The Subsidy System in Egypt: Alternatives for Reform, Policy Viewpoint, The Egyptian Center for Economic Studies.

Krishnan N., Olivieri S. and Ramadan R., 2017. Estimating the Welfare Costs of Reforming the Iraq Public Distribution System: A Mixed Demand Approach. World Bank Policy Research Working Paper No. 8106, 2017.

Matsuda T., 2004. Incorporating Generalized Marginal Budget Shares in a Mixed Demand System, American Journal of Agricultural Economics, 86(4): 1117-1126.

Ministry of Supply and Internal Trade, 2014. http:// www.msit.gov.eg.

Ministry of Supply and Internal Trade, 2015. Monthly Bulletin.

Ministry of Finance, 2013. Financial Monthly Bulletin. Ministry of Finance, 2015. Financial Monthly Bulletin. Moschini G.C. and Rizzi P.L., 2006. Coherent Specification of a Mixed Demand System: The StoneGeary Model, in Essays in Honor of Stanley R. Johnson, ed. Matthew T. Holt and JeanPaul Chavas. Berkeley: Berkeley Electronic Press.

Moschini G.C. and Rizzi P.L., 2007. Deriving a flexible mixed demand system: The normalized Quadratic Model, American Journal of Agricultural Economics, 89(4): 1034-1045.

Omar D.A., 2012. Food Subsidy Reform: Case of Egypt, Master Thesis, American University in Cairo.

Oliver K., 2015. Targeting the Egyptian Food Subsidy System: Urban Versus Rural Reform, UChicago Undergraduate Business Journal, Spring 2015.

Ramadan R., 2015. Demand and Supply Challenges of Food Security in Egypt, Economic Literature Review, Review No. 2, The Egyptian Center for Economic Studies. 
Ramadan R. and Thomas A., 2011. Evaluating the Impact of Reforming the Food Subsidy Program in Egypt: A Mixed Demand Approach, Food Policy, October 2011, 36(5): 638-646.

Shonkwiler J. and Yen S.T., 1999. Two-Step Estimation of a Censored System of Equations, American Journal of Agricultural Economics, 81(4): 972982.

Sivakul A., 2012. Cash versus In-Kind Transfers: The Case of Bangladesh, Department of Economics, University of Oxford.
Standing G., 2012. Cash Transfers A Review of the Issues in India, Social Policy Working Paper Series UNICEF.

The Information and Decision Support Center, 2012. The Subsidy System in Egypt. Facts and Perceptions, Monthly Report No. 63.

World Bank, 2010. Egypt's Food Subsidies: Benefit, Incidence, and Leakages, Report No. 57446.

World Bank, 2015. Building Resilience and Opportunity: Social Protection Reform in Egypt, Washington DC: The World Bank.

Appendix: Estimated Income, Own Price and Cross Elasticities

Table A1 - Income Elasticities.

\begin{tabular}{|c|c|c|c|c|c|c|c|c|}
\hline & \multicolumn{4}{|c|}{ Free Market Goods } & \multicolumn{4}{|c|}{ Rationed Goods } \\
\hline & Rice & Oil & Sugar & Pasta & Rice & Oil & Sugar & Pasta \\
\hline Quintile & \multicolumn{8}{|c|}{ Urban } \\
\hline 1 & 0.47 & 1.74 & 0.90 & 0.76 & -0.13 & -0.01 & 0.04 & 0.02 \\
\hline 2 & 0.36 & 1.24 & 0.66 & 0.28 & -0.12 & 0.00 & 0.07 & 0.05 \\
\hline 3 & 0.19 & 0.86 & 0.47 & 0.33 & -0.17 & 0.00 & 0.10 & 0.07 \\
\hline 4 & 0.17 & 0.44 & 0.28 & 0.76 & -0.35 & -0.02 & 0.12 & 0.10 \\
\hline \multirow[t]{2}{*}{5} & 0.13 & 0.21 & 0.16 & 0.84 & -0.57 & -0.16 & 0.17 & 0.20 \\
\hline & \multicolumn{8}{|c|}{ Rural } \\
\hline 1 & 0.46 & 2.34 & 0.94 & 0.73 & -0.10 & 0.00 & 0.04 & 0.02 \\
\hline 2 & 0.33 & 1.56 & 0.59 & 0.32 & -0.13 & -0.08 & 0.08 & 0.07 \\
\hline 3 & 0.21 & 1.14 & 0.50 & 0.11 & -0.12 & -0.04 & 0.10 & 0.08 \\
\hline 4 & 0.15 & 0.53 & 0.25 & 0.28 & -0.14 & -0.03 & 0.12 & 0.11 \\
\hline 5 & 0.16 & 0.36 & 0.25 & 0.40 & -0.47 & -0.03 & 0.14 & 0.15 \\
\hline
\end{tabular}

Source: Computed by the authors using HEICS 2010/2011.

Table A2 - Own price and Cross Price Elasticities of Free Market Goods.

\begin{tabular}{|l|l|c|c|c|c|c|c|c|c|c|c|}
\hline & & \multicolumn{9}{|c|}{ Urban } & \multicolumn{1}{c|}{ Rural } \\
\hline & & $\begin{array}{c}\text { lst } \\
\text { quintile }\end{array}$ & 2 & 3 & 4 & $\begin{array}{c}5 \text { th } \\
\text { quintile }\end{array}$ & $\begin{array}{c}\text { lst } \\
\text { quintile }\end{array}$ & 2 & 3 & 4 & $\begin{array}{c}5 \text { th } \\
\text { quintile }\end{array}$ \\
\hline Rice & rice & 0.06 & 0.01 & 0.00 & 0.01 & 0.00 & 0.05 & 0.02 & 0.01 & 0.00 & 0.01 \\
& oil & 0.28 & 0.12 & 0.08 & 0.11 & 0.15 & 0.24 & 0.14 & 0.08 & 0.07 & 0.15 \\
& sugar & -0.31 & -0.11 & -0.05 & -0.04 & -0.02 & -0.28 & -0.13 & -0.07 & -0.04 & -0.02 \\
& pasta & -0.43 & -0.45 & -0.34 & -0.52 & -0.69 & -0.40 & -0.45 & -0.35 & -0.38 & -0.81 \\
\hline Oil & rice & 0.58 & 0.17 & 0.08 & 0.08 & 0.06 & 0.92 & 0.21 & 0.08 & 0.03 & 0.09 \\
& oil & -1.92 & -0.65 & -0.35 & -0.24 & -0.24 & -3.06 & -0.75 & -0.35 & -0.26 & -0.20 \\
& sugar & -1.08 & -0.35 & -0.18 & -0.14 & -0.13 & -1.78 & -0.41 & -0.20 & -0.14 & -0.14 \\
& pasta & 0.95 & -0.69 & -0.96 & -0.68 & -0.33 & 2.11 & -0.69 & -1.30 & -0.61 & -1.03 \\
\hline Sugar & rice & -0.49 & -0.24 & -0.17 & -0.12 & -0.09 & -0.40 & -0.21 & -0.15 & -0.09 & -0.10 \\
& oil & -0.46 & -0.17 & -0.10 & -0.06 & -0.02 & -0.38 & -0.15 & -0.09 & -0.06 & -0.04 \\
& sugar & 0.35 & 0.15 & 0.12 & 0.09 & 0.07 & 0.22 & 0.13 & 0.10 & 0.04 & 0.08 \\
& pasta & -0.16 & -0.50 & -0.60 & -0.58 & -0.53 & -0.04 & -0.43 & -0.62 & -0.33 & -0.73 \\
\hline Pasta & rice & -0.01 & 0.01 & 0.00 & 0.02 & -0.04 & -0.01 & 0.01 & 0.04 & 0.01 & 0.07 \\
& oil & 0.50 & 0.42 & 0.54 & 0.93 & 1.31 & 0.52 & 0.43 & 0.40 & 0.56 & 1.04 \\
& sugar & 0.41 & 0.31 & 0.36 & 0.65 & 0.75 & 0.42 & 0.32 & 0.30 & 0.42 & 0.69 \\
& pasta & -1.54 & -1.17 & -1.66 & -3.74 & -5.93 & -1.56 & -1.19 & -1.02 & -1.95 & -4.44 \\
\hline
\end{tabular}

Source: Computed by the authors using HEICS 2010/2011. 
Table A3 - Own price and Cross Price Elasticities of Ration Goods.

\begin{tabular}{|l|l|c|c|c|c|c|c|c|c|c|c|c|}
\hline & & \multicolumn{9}{|c|}{ Urban } & \multicolumn{1}{c|}{ Rural } \\
\hline & & $\begin{array}{c}\text { lst } \\
\text { quintile }\end{array}$ & 2 & 3 & 4 & $\begin{array}{c}5 \text { th } \\
\text { quintile }\end{array}$ & $\begin{array}{c}\text { lst } \\
\text { quintile }\end{array}$ & 2 & 3 & 4 & $\begin{array}{c}5 \text { th } \\
\text { quintile }\end{array}$ \\
\hline Rice & rice & 0.01 & 0.01 & 0.02 & 0.02 & 0.03 & 0.01 & 0.02 & 0.02 & 0.01 & 0.04 \\
& oil & -0.01 & -0.02 & -0.03 & -0.04 & -0.05 & -0.01 & -0.02 & -0.03 & -0.01 & -0.07 \\
& sugar & 0.03 & 0.07 & 0.10 & 0.13 & 0.20 & 0.04 & 0.07 & 0.09 & 0.12 & 0.21 \\
& pasta & 0.00 & 0.00 & 0.00 & 0.02 & 0.03 & 0.00 & 0.01 & 0.00 & 0.01 & 0.02 \\
\hline Oil & rice & 0.00 & -0.01 & -0.01 & -0.01 & 0.01 & 0.00 & -0.05 & -0.01 & 0.00 & -0.01 \\
& oil & 0.00 & -0.01 & -0.01 & -0.01 & -0.01 & 0.00 & 0.02 & -0.01 & -0.03 & -0.03 \\
& sugar & -0.01 & -0.01 & -0.02 & -0.03 & -0.04 & -0.01 & -0.05 & -0.02 & -0.02 & -0.05 \\
& pasta & 0.01 & 0.02 & 0.03 & 0.04 & 0.14 & 0.01 & 0.01 & 0.01 & 0.05 & 0.06 \\
\hline Sugar & rice & 0.03 & 0.07 & 0.10 & 0.12 & 0.16 & 0.04 & 0.06 & 0.09 & 0.12 & 0.16 \\
& oil & -0.02 & -0.04 & -0.05 & -0.07 & -0.13 & -0.02 & -0.04 & -0.04 & -0.07 & -0.11 \\
& sugar & 0.00 & -0.01 & -0.01 & -0.01 & -0.01 & 0.00 & 0.01 & -0.01 & -0.01 & -0.01 \\
& pasta & 0.00 & -0.01 & -0.01 & -0.01 & -0.03 & 0.00 & 0.00 & 0.00 & -0.02 & -0.02 \\
\hline Pasta & rice & -0.01 & -0.02 & -0.03 & -0.03 & -0.05 & -0.01 & 0.00 & -0.02 & -0.03 & -0.05 \\
& oil & 0.03 & 0.06 & 0.09 & 0.13 & 0.20 & 0.03 & 0.05 & 0.09 & 0.12 & 0.21 \\
& sugar & 0.00 & 0.00 & -0.01 & -0.01 & -0.01 & 0.00 & 0.01 & -0.01 & -0.01 & -0.01 \\
& pasta & 0.00 & -0.01 & -0.01 & -0.01 & -0.04 & 0.00 & 0.00 & 0.00 & -0.02 & -0.02 \\
\hline
\end{tabular}

Source: Computed by the authors using HEICS 2010/2011.

Table A4 - Cross Price Elasticities for Free Market Goods with Respect to the Rationed Goods.

\begin{tabular}{|l|l|c|c|c|c|c|c|c|c|c|c|c|}
\hline & & \multicolumn{9}{|c|}{ Urban } & \multicolumn{1}{c|}{ Rural } \\
\hline & & $\begin{array}{c}\text { lst } \\
\text { quintile }\end{array}$ & 2 & 3 & 4 & $\begin{array}{c}5 \text { th } \\
\text { quintile }\end{array}$ & $\begin{array}{c}\text { Ist } \\
\text { quintile }\end{array}$ & 2 & 3 & 4 & $\begin{array}{c}5 \text { th } \\
\text { quintile }\end{array}$ \\
\hline Rice & rice & -0.17 & -0.11 & -0.05 & -0.04 & -0.02 & -0.17 & -0.11 & -0.07 & -0.04 & -0.04 \\
& oil & 0.80 & 0.50 & 0.27 & 0.26 & 0.19 & 0.77 & 0.52 & 0.31 & 0.23 & 0.27 \\
& sugar & -0.15 & -0.09 & -0.05 & -0.04 & -0.02 & -0.14 & -0.10 & -0.06 & -0.03 & -0.03 \\
& pasta & -0.14 & -0.13 & -0.06 & -0.04 & -0.04 & -0.16 & -0.12 & -0.05 & -0.07 & -0.05 \\
\hline Oil & rice & 3.97 & 1.91 & 1.28 & 0.76 & 0.55 & 5.65 & 2.23 & 1.42 & 0.78 & 0.71 \\
& oil & -0.12 & 0.02 & 0.00 & 0.02 & -0.03 & -0.11 & -0.10 & 0.09 & -0.02 & 0.01 \\
& sugar & -0.33 & -0.20 & -0.14 & -0.07 & -0.03 & -0.45 & -0.23 & -0.22 & -0.08 & -0.06 \\
& pasta & -0.40 & -0.19 & -0.16 & -0.07 & -0.07 & -0.63 & -0.33 & -0.12 & -0.13 & -0.09 \\
\hline Sugar & rice & 0.95 & 0.55 & 0.42 & 0.28 & 0.17 & 0.68 & 0.45 & 0.40 & 0.20 & 0.22 \\
& oil & -0.06 & -0.06 & -0.01 & 0.00 & -0.02 & -0.10 & -0.05 & 0.03 & -0.02 & -0.01 \\
& sugar & -0.05 & -0.05 & -0.04 & -0.02 & 0.00 & -0.06 & -0.06 & -0.07 & -0.01 & -0.01 \\
& pasta & 0.12 & 0.02 & 0.01 & 0.01 & 0.02 & 0.03 & 0.03 & -0.01 & 0.01 & 0.01 \\
\hline Pasta & rice & -0.71 & -0.80 & -0.83 & -1.15 & -0.80 & -0.82 & -0.80 & -0.92 & -0.88 & -1.06 \\
& oil & -0.33 & -0.37 & -0.38 & -0.59 & -0.52 & -0.34 & -0.40 & -0.43 & -0.48 & -0.47 \\
& sugar & -0.11 & -0.10 & -0.10 & -0.15 & -0.12 & -0.13 & -0.12 & -0.10 & -0.12 & -0.15 \\
& pasta & -0.16 & -0.16 & -0.12 & -0.21 & -0.25 & -0.16 & -0.19 & -0.10 & -0.21 & -0.26 \\
\hline
\end{tabular}

Source: Computed by the authors using HEICS 2010/2011.

Table A5 - Cross Price Elasticties of Rationed Price with Respect to Free Market Price.

\begin{tabular}{|l|l|c|c|c|c|c|c|c|c|c|c|c|}
\hline & & \multicolumn{9}{c|}{ Urban } & \multicolumn{1}{c|}{ Rural } \\
\hline \multirow{2}{*}{ Rice } & & $\begin{array}{c}\text { 1st } \\
\text { quintile }\end{array}$ & 2 & 3 & 4 & $\begin{array}{c}5 \text { th } \\
\text { quintile }\end{array}$ & $\begin{array}{c}\text { 1st } \\
\text { quintile }\end{array}$ & 2 & 3 & 4 & $\begin{array}{c}5 \text { th } \\
\text { quintile }\end{array}$ \\
& rice & 0.03 & 0.02 & 0.03 & 0.04 & 0.07 & 0.02 & 0.03 & 0.05 & 0.04 & 0.05 \\
& oil & -0.18 & -0.26 & -0.38 & -0.56 & -0.96 & -0.18 & -0.25 & -0.29 & -0.40 & -0.80 \\
& sugar & -0.12 & -0.16 & -0.22 & -0.35 & -0.55 & -0.12 & -0.16 & -0.19 & -0.25 & -0.49 \\
& pasta & 0.33 & 0.46 & 0.65 & 0.95 & 1.57 & 0.34 & 0.44 & 0.52 & 0.70 & 1.32 \\
\hline Oil & rice & -0.05 & -0.07 & -0.10 & -0.16 & -0.27 & -0.05 & 0.08 & -0.05 & -0.14 & -0.23 \\
& oil & 0.00 & 0.00 & 0.00 & 0.00 & 0.00 & 0.00 & 0.00 & 0.00 & 0.00 & -0.01 \\
& sugar & 0.00 & 0.00 & 0.00 & 0.00 & -0.02 & 0.00 & 0.00 & 0.00 & -0.01 & 0.00 \\
& pasta & 0.05 & 0.08 & 0.11 & 0.16 & 0.35 & 0.05 & 0.04 & 0.10 & 0.17 & 0.24 \\
\hline Sugar & rice & 0.01 & 0.02 & 0.03 & 0.04 & 0.06 & 0.01 & -0.02 & 0.02 & 0.03 & 0.05 \\
& oil & 0.01 & 0.02 & 0.03 & 0.04 & 0.05 & 0.01 & 0.02 & 0.02 & 0.03 & 0.05 \\
& sugar & 0.01 & 0.01 & 0.01 & 0.01 & 0.00 & 0.01 & 0.01 & 0.01 & 0.01 & 0.00 \\
& pasta & -0.02 & -0.03 & -0.05 & -0.07 & -0.11 & -0.02 & -0.02 & -0.04 & -0.04 & -0.08 \\
\hline Pasta & rice & 0.02 & 0.03 & 0.04 & 0.06 & 0.10 & 0.02 & -0.01 & 0.02 & 0.05 & 0.08 \\
& oil & 0.01 & 0.02 & 0.03 & 0.04 & 0.06 & 0.01 & 0.02 & 0.02 & 0.03 & 0.06 \\
& sugar & -0.02 & -0.02 & -0.04 & -0.06 & -0.08 & -0.02 & -0.02 & -0.03 & -0.04 & -0.08 \\
& pasta & 0.01 & 0.01 & 0.00 & -0.02 & -0.08 & 0.01 & 0.01 & 0.00 & -0.01 & -0.05 \\
\hline
\end{tabular}

Source: Computed by the authors using HEICS 2010/2011. 